\title{
Prevalence and Genetic Diversity of Norovirus in Acute Gastroenteritis Cases in the Southwest Province of Turkey
}

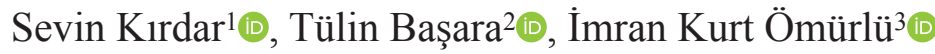 \\ ${ }^{1}$ Department of Medical Microbiology, Faculty of Medicine, Aydın Adnan Menderes University, Aydın, Turkey
${ }^{2}$ Laboratory of Medical Microbiology Training and Research Hospital, Aydın Adnan Menderes University, Aydın, Turkey
${ }^{3}$ Department of Biostatistics, Faculty of Medicine, Aydın Adnan Menderes University, Aydın, Turkey
}

\begin{abstract}
Aims: Noroviruses may cause both epidemic and sporadic acute gastroenteritis globally. Thus, this study evaluated the prevalence of norovirus in stool samples of hospitalized patients with acute gastroenteritis in Aydin, Turkey using enzyme-linked immunoassay (ELISA) and real-time reverse transcription-polymerase chain reaction (rRT-PCR) and genotyped positive samples to detect which genotypes have currently circulated.

Methods: This retrospective descriptive study collected 92 stool samples from patients with acute gastroenteritis symptoms from Aydın Adnan Menderes University Hospital from September 2017 to May 2019. The samples were tested using the commercial Third Generation Ridascreen norovirus ELISA and rRT-PCR. Positive samples were
\end{abstract}

genotyped by sequencing of conventional positive RT-PCR products followed by phylogenetic analysis.

Results: Of the 92 samples, 5 (5.4\%) using ELISA and 12 (13\%) using rRT-PCR tested positive for norovirus. All positive samples were genogroup II (GII). Two norovirus positive samples were genotyped successfully using DNA sequencing of the nested conventional PCR products. One sample (GII/Hu/TR/2019/Aydin25) could be categorized as GII.3 and the other (GII/Hu/TR/2019/Aydin20) as GII.13.

Conclusion: rRT-PCR testing of stool samples is more sensitive than Ridascreen ELISA. Data from our study provide protocols for how to study norovirus epidemiology.

\section{INTRODUCTION}

Enteric viruses, such as enteric adenovirus, rotavirus, norovirus, astrovirus, and sapovirus are the most common etiologic agents of childhood viral gastroenteritis. ${ }^{1}$ Norovirus is also one the most frequent causes of acute gastroenteritis (AGE) outbreaks in semiclosed settings, such as schools, hospitals, nursing homes, worship places, cruise ships, and military facilities.

Moreover, norovirus has emerged as the most frequent cause of AGE in children in countries with public vaccination programs including rotavirus vaccine. ${ }^{2}$ Norovirus may lead to severe AGE in developing countries, with an estimated 70,000-210,000 deaths in children annually. ${ }^{3}$

Noroviruses belong to the family Caliciviridae. Norovirus generally show high genetic variability and are classified into 10 genogroups (GI to GX) based on the capsid (VP1) protein. They can be further divided into 48 capsid genotypes based on VP1 and 60 P-types. ${ }^{4}$
Robust cell culture or small animal model is unavailable; however, successful replication of human norovirus in human intestinal enteroids has been reported..$^{5}$ Norovirus can be detected by laboratory assays, such as enzyme-linked immunoassay (ELISA) and immunochromatographic assays, that detect the viral antigen, and by molecular tests, such as real-time reverse transcriptionpolymerase chain reaction (rRT-PCR), which is accepted as the gold standard for norovirus diagnosis. ${ }^{3}$

This study aimed to determine the presence of norovirus by ELISA and rRT-PCR methods in AGE cases in Aydın, Turkey. Additionally, positive samples were genotyped to understand which genotypes have currently circulated in our hospital.

\section{MATERIAL AND METHODS}

This retrospective descriptive study was conducted between September 2017 and May 2019. Stool samples were collected from patients ( $0-83$ years old) who are admitted with AGE symptoms

\footnotetext{
Corresponding author: Sevin Kırdar, Department of Medical Microbiology, Faculty of Medicine, Aydın Adnan Menderes University, Aydın, Turkey e-mail: dr.sevinkirdar@gmail.com

Received: August 19, 2021 Accepted: December 3, 2021 Available Online Date: March, 14, 2022 • DOI: 10.4274/balkanmedj.galenos.2021.2021-8-22

Available at www.balkanmedicaljournal.org

ORCID iDs of the authors: S.K.- 0000-0002-4511-578X; T.B.- 0000-0003-3395-5332; İ.K.Ö.- 0000-0003-2887-6656.

Cite this article as:

Kırdar S, Başara T, Kurt Ömürlü İ. Prevalence and Genetic Diversity of Norovirus in Acute Gastroenteritis Cases in the Southwest Province of Turkey.

Balkan Med J.; 2022; 39(2):153-6.

Copyright@Author(s) - Available online at http://balkanmedicaljournal.org/
} 
to the Aydin Adnan Menderes University, School of Medicine Hospital. This study included 92 fecal samples, which are stored at $-80{ }^{\circ} \mathrm{C}$ until laboratory analysis. This study was approved by the Clinical Research Ethical Review Committee of the Aydin Adnan Menderes University (No:2017/1229) and supported by Aydin Adnan Menderes University Research Fund (Project number: 17058).

Fecal samples of patients with AGE were tested for norovirus by Ridascreen norovirus Antigen ELISA kit (R-Biopharm, Darmstadt, Germany), which can qualitatively determine norovirus genogroup I and II viruses. Tests were performed following the manufacturer's instructions. The cut-off value was determined by adding 0.150 above the measured optical density (OD) value of the negative control. Samples with OD above the cut-off value were accepted as positive for the norovirus antigen. Co-infections with adenovirus and rotavirus were detected by an immunochromatographic test (Rotavirus and Adenovirus Combo Rapid Test, Hangzhou, China).

RNA extraction was done by Bosphore Viral RNA Extraction Spin Kit (Anatolia Geneworks, Istanbul, Turkey) using the Magnesia ${ }^{\circledR}$ instrument (Anatolia Geneworks, Istanbul, Turkey). Internal controls were included in each sample during the extraction step. Norovirus RNA was then amplified by the Bosphore ${ }^{\circledR}$ norovirus Detection Kit v1 in Montania 4896 instrument (Anatolia Geneworks). PCR amplification was performed following the manufacturer's instructions.

Conventional RT-PCR assays were performed to amplify a partial region of the VP1 gene using primer pairs NV-GIIF1 (5' GGG AGG GCG ATC GCA ATC T 3') and NV-GIIR1 (5' CCR CCI GCA TRICCR TTR TAC AT 3'), which amplify a 5'-region of VP1. ${ }^{6}$ Additionally, JV12 (5' ATA CCA CTATGA TGC AGA TTA 3') and JV13 5' TCA TCATCA CCA TAG AAA GAG 3') primers were used to amplify a partial region of the RdRp gene. Extracted RNA was first converted into complement DNA (cDNA) using the Thermo First Strand cDNA kit. The PCR conditions for partial VP1 gene amplification included initial denaturation of the nucleic acid for $5 \mathrm{~min}$ at $95^{\circ} \mathrm{C}$, followed by 35 cycles at $95^{\circ} \mathrm{C}$ for $30 \mathrm{sec}, 49^{\circ} \mathrm{C}$ for $30 \mathrm{sec}, 72^{\circ} \mathrm{C}$ for $1 \mathrm{~min}$, and a final extension of $7 \mathrm{~min}$ at $72^{\circ} \mathrm{C}$. Nucleic acid was first denatured for $5 \mathrm{~min}$ at $95^{\circ} \mathrm{C}$ to amplify the partial gene, followed by 35 cycles of PCR at $95{ }^{\circ} \mathrm{C}$ for $30 \mathrm{sec}, 44$ ${ }^{\circ} \mathrm{C}$ for $30 \mathrm{sec}, 72{ }^{\circ} \mathrm{C}$ for $1 \mathrm{~min}$, and a final extension of $7 \mathrm{~min}$ at 72 ${ }^{\circ} \mathrm{C}$. PCR products were separated and visualized on a $1 \%$ agarose gel and then purified using a commercial kit (Invitrogen Combo Purification kit). Purified products were processed to Sanger sequencing with ABI 3100 Genetic Analyzer (Applied Biosystems, USA)

Obtained sequences were checked in BLAST implemented in the GenBank database. The phylogenetic tree was constructed with norovirus reference strains using a computer-based tool (MEGA v10.0) to understand the genotypes of our sequences.

Descriptive statistics were shown as frequency, percentage, median $\left(25^{\text {th }}-75^{\text {th }}\right.$ percentile), and minimum and maximum values. The chi-square or Fisher exact test was used to compare the categorical variables. A $p$-value of $<0.05$ was considered significant.

\section{RESULTS}

During the study period, fecal specimens from 92 patients with AGE were collected, of which $55(59.8 \%)$ were males and 37 $(40.2 \%)$ were females. The age of patients ranged from 0 to 83 years with a median age of 2 years.

Of the 92 samples, 5 (5.4\%) using ELISA and 12 (13\%) using rRTPCR tested positive for norovirus. Five patients with an ELISA positive result were all males, whereas 10 were males and 2 females in the 12 patients with positive real-time RT-PCR. A statistically significant difference was found between norovirus positivity by ELISA and age groups $(P=0.002)$; however, positivity by rRT-PCR between age groups was not statistically significant $(P$ $=0.182$ ) (Table 1). Samples from the 0-5 years age group most frequently tested positive for norovirus; however, no significant difference was found in the positivity rate between the $0-2$ years and 3-5 years age group for either the samples tested by ELISA or by rRT-PCR ( $P=1.000$ for both tests, data not shown). Overall, 12 samples tested positive for GII, of which two (GII/Hu/TR/2019/ Aydin20 and GII/Hu/TR/2019/Aydin25) samples were successfully sequenced. Using BLAST, 1 sequence (GII/Hu/TR/2019/Aydin25) had the highest sequence identity with GII.3 viruses, whereas 20 was identical to GII.13 in sequence GII/Hu/TR/2019/Aydin (Figure 1). The following accession numbers were assigned by GenBank (GII/Hu/TR/2019/Aydin20) MT815529 (VP1), MW392526 (RdRp); GII/Hu/TR/2019/Aydin25 MT815530(VP1), MW392525 (RdRp).

Norovirus was detected throughout the year, but its prevalence was highest in the winter and spring (Table 2). No statistically significant difference was found between norovirus positivity and seasons $(P=0.192)$. Co-infections with rotavirus or adenovirus were detected in 9 cases.

TABLE 1. Detection of Norovirus by ELISA and Real-time RT-PCR According to Age Groups

\begin{tabular}{lcccc}
\hline Age groups & \multicolumn{2}{c}{ ELISA results $(\mathrm{n}, \%)^{*}$} & \multicolumn{2}{c}{ PCR results $(\mathrm{n}, \%)^{* *}$} \\
\hline & Positive & Negative & Positive & Negative \\
\hline $0-5$ & $3(3.3)$ & $68(73.9)$ & $8(8.7)$ & $63(68.5)$ \\
$6-17$ & - & $16(17.4)$ & $2(2.2)$ & $14(15.2)$ \\
$\geq 18$ & $2(2.2)$ & $3(3.3)$ & $2(2.2)$ & $3(3.3)$ \\
Total & $5(5.4)$ & $87(94.6)$ & $12(13)$ & $80(87)$ \\
\hline${ }^{*} P=0.002 ; * * P=0.182$ & & & \\
\hline
\end{tabular}

TABLE 2. Seasonal Distribution of Real-time RT-PCR Results for Norovirus

\begin{tabular}{lccc}
\hline Season & \multicolumn{3}{c}{ PCR results $(\mathrm{n}, \%)$} \\
\hline Winter & Negative & Positive & Total \\
Spring & $22(75.9)$ & $7(24.1 \%)$ & $29(100 \%)$ \\
Summer & $46(92 \%)$ & $4(13.7 \%)$ & $50(100 \%)$ \\
Autumn & $5(100 \%)$ & 0 & $5(100 \%)$ \\
Total & $7(87.5 \%)$ & $1(3.4 \%)$ & $8(100 \%)$ \\
\hline
\end{tabular}



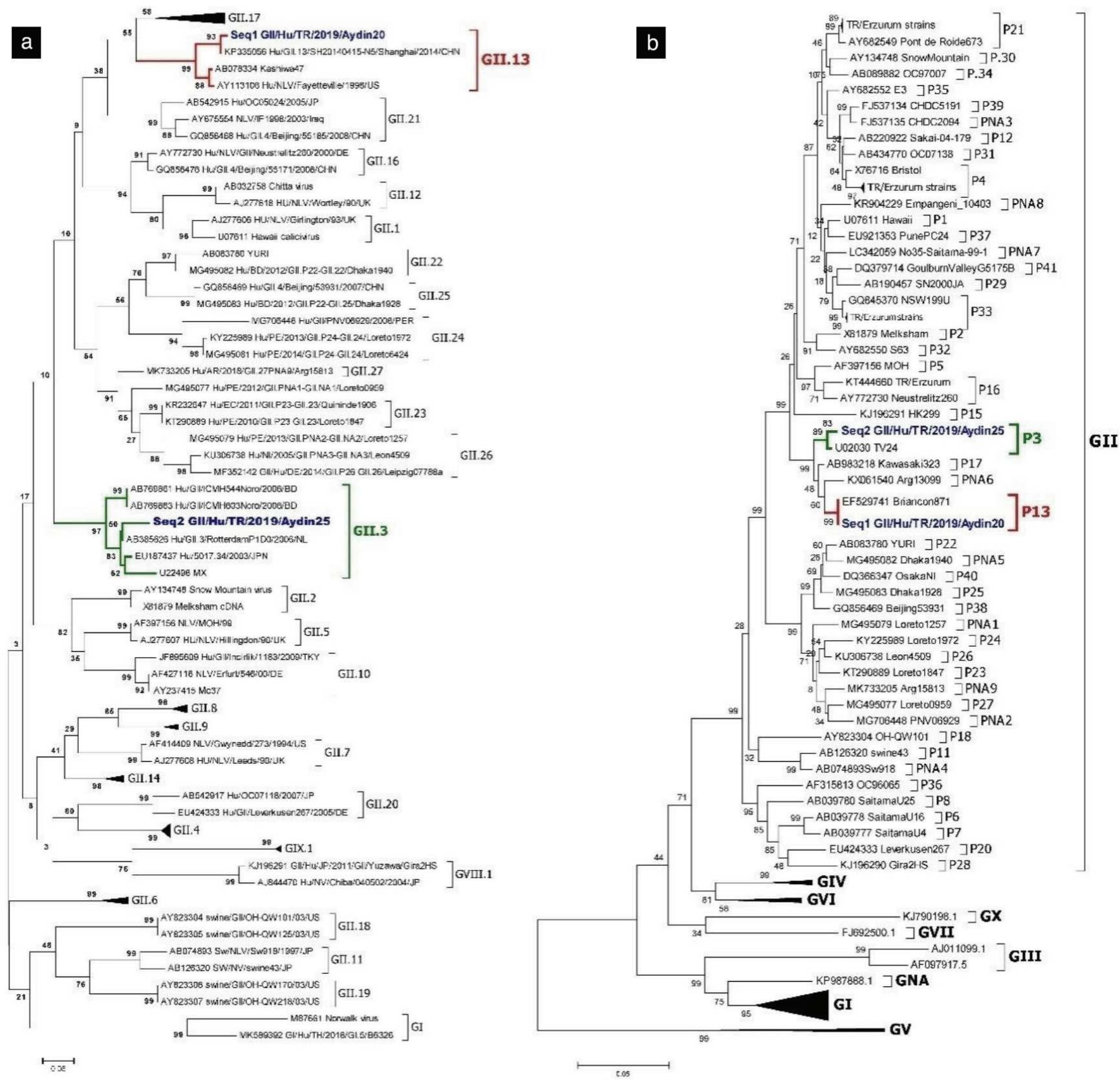

FIG. 1. (a) Molecular phylogenetic analysis based on VP1 by Maximum Likelihood method. (b) Molecular phylogenetic analysis based on RdRp by Maximum Likelihood method. Turkish new sequences, GII/Hu/TR/2019/Aydin20 and GII/Hu/TR/2019/Aydin25, were categorized as GII.13 and GII.3, respectively.

\section{DISCUSSION}

The present study determined the prevalence and genetic diversity of norovirus that is detected in hospitalized patients with AGE in Aydin, Turkey. The Ridascreen ELISA had a sensitivity of $42 \%$ and a specificity of $100 \%$ compared to the rRT-PCR. All rRT-PCR positive samples $(100 \%)$ were positive for GII. The two samples that were successfully amplified by conventional RT-PCR could be genotyped as GII.3 and GII.13.
Based on a systematic review, norovirus causes AGE in approximately $20 \%-24 \%$ of patients in community or outpatient clinics and $17 \%$ of hospitalized patients worldwide. ${ }^{3}$ The first norovirus outbreak was reported from central Anatolia in 2008 in Turkey. ${ }^{7}$ Several water and foodborne norovirus outbreaks have been reported since then. ${ }^{8-10}$ Altindis et al. ${ }^{11}$ reported norovirus in $17 \%$ of sporadic AGE in Turkey. 
Previous studies used ELISA and revealed the rate of norovirus ranged from $9.7 \%$ to $26 \% .^{7,12-14}$ Our study revealed 5 (5.4\%) stool samples that were positive for norovirus using ELISA, which was similar to a recent report from Canakkale. ${ }^{12}$ Previous norovirus prevalence determined by rRT-PCR ranged from $15.1 \%$ to $33.4 \% .^{7,11-13,15,16}$ Using rRT-PCR, a similar positivity rate was found in our study. ${ }^{11-13}$ The sensitivity rate of the ELISA test was similar to other studies, which reported the sensitivity rates for Rida screen norovirus kit that range from $31.6 \%$ to $65.3 \%$, respectively. ${ }^{17}$ The ELISA kit showed a lower sensitivity than reported by Dimitriadis and Marshall ${ }^{18}$ in Australia (71\%), Aksu et al. ${ }^{12}$ in Turkey (60\%), and Zhang et al..$^{19}$ in China (96\%), which was similar to a study conducted by Rovida et al. ${ }^{20}$ Most studies, including ours, a $>90 \%$ ELISA specificity. ${ }^{7,12,16}$ Due to its high sensitivity and specificity, rRT-PCR is considered the gold standard for norovirus detection.

Globally, GII noroviruses are associated with $90 \%-100 \%$ of all infections ${ }^{12,16,21}$ The limited studies from Turkey that performed genotyping primarily detected GII.4, GII.6, GII.16, and GII.21 viruses. ${ }^{12,15-16}$ To the best of our knowledge, this is the first report on detected GII.3 and GII.13 genotypes of norovirus infections in Turkey.

Co-infections with two or more enteric pathogens are common, and the increasing use of molecular techniques has revealed even higher rates. ${ }^{22}$ Our study detected co-infections in $9(9.8 \%)$ norovirus rRTPCR-positive samples. The most common co-infections were with rotavirus $(\mathrm{n}=8)$ and adenovirus $(\mathrm{n}=1)$.

Our study has several limitations. The number of participants with AGE was small and we could only successfully sequence 2 samples, which indicates that the used primers were suboptimal for robust genotyping.

In summary, our study detected and genotyped noroviruses in Aydin, Turkey with tourism and increased social interactions between the Aegean part of Turkey and Europe, thereby increasing the risk of norovirus transmission. Our pilot data will increase the knowledge of the importance of norovirus infections in Turkey.

Ethics Committee Approval: This study was approved by the Clinical Research Ethical Review Committee of the Aydin Adnan Menderes University (No:2017/1229) and supported by Aydın Adnan Menderes University Research Fund (Project number: 17058).

Data Sharing Statement:: The data that support the findings of this study are available from the corresponding author upon reasonable request.

Patient Consent for Publication: Written informed consent was obtained from the patients.

Author Contributions: Concept - S.K.; Design - S.K., T.B.; Supervision - S.K.; Data Collection and/or Processing - T.B.; Analysis and/or Interpretation - S.K., T.B. İ.K.Ö.; Literature Review - S.K., T.B.; Writing - S.K., T.B.; Critical Review - S.K., I.K.Ö.

Conflict of Interest: No conflict of interest was declared by the authors.

Funding: The authors declared that this study received no financial support.

\section{REFERENCES}

1. Alp Avc1 G, Akbaba M. Incidence of Rotavirus, enteric adenovirus and Norovirus in children with acute gastroenteritis under five years. TMCD. 2018;48:264-272. [Crossref]

2. Parra GI, Squires RB, Karangwa CK, et al. Static and evolving Norovirus genotypes: Implications for epidemiology and immunity. PLOS Pathog. Sestak K, editor 2017;13:e1006136. [Crossref]

3. Yoon SH, Kim HR, Ahn JG. Diagnostic accuracy of immunochromatographic tests for thedetection of Norovirus in stool specimens: A systematic review and metaanalysis. Microbiol Spectr. 2021;9:e0046721. [Crossref]

4. Chhabra P, de Graaf M, Parra GI, et al. Updated classification of Norovirus genogroups and genotypes. J Gen Virol. 2019;100:1393-1406. [Crossref]

5. Oka T, Stoltzfus GT, Zhu C, Jung K, Wang Q, Saif LJ. Attempts to grow human noroviruses, a Sapovirus, and a bovine Norovirus in vitro. PLOS ONE. 2018;13:e0178157. [Crossref]

6. Kim SH, Cheon DS, Kim JH, et al. Outbreaks of gastroenteritis that occurred during school excursions in Korea were associated with several waterborne strains of Norovirus. J Clin Microbiol. 2005;43:4836-4839. [Crossref]

7. Uyar Y, Carhan A, Ozkaya E, Ertek M. Evaluation of laboratory diagnosis of the first Norovirus outbreak in Turkey in 2008. Mikrobiyol Bul. 2008;42:607-615. [Crossref]

8. Gonen I. Management of a large outbreak caused by Norovirus and Campylobacter jejuni occurred in a rural area in Turkey. Nobel Med. 2013;9:47-51. [Crossref]

9. Can G, Yavuzyilmaz A, Cinarka H, Dereli M, Topbas M, Ozgun S. Norovirus outbreak investigation in Surmene District of Trabzon Province July 2010. TAF Prev Med Bull. 2011;10:501. [Crossref]

10. Ahmed SF, Klena JD, Mostafa M, et al. Viral gastroenteritis associated with genogroup II Norovirus among U.S. Military personnel in Turkey, 2009. PLOS ONE. 2012;7:e35791. [Crossref]

11. Altindis M, Bányai K, Kalayci R, et al. Frequency of Norovirus in stool samples from hospitalized children due to acute gastroenteritis in Anatolia, Turkey, 2006-2007. Scand J Infect Dis. 2009;41:685-658. [Crossref]

12. Aksu A, Akçalı A. Detection of norovirus infections in Canakkale with ELISA and RT-PCR. Cukurova Med J. 2016;41:533-538. [Crossref]

13. Ozkul AA, Kocazeybek BS, Turan N, et al. Frequency and phylogeny of Norovirus in diarrheic children in Istanbul, Turkey. J Clin Virol. 2011;51:160-164. [Crossref]

14. Altay A, Bozdayı G, Meral M, et al. Investigation of Norovirus infection incidence among $0-5$ years old children with acute gastroenteritis admitted to two different hospitals in ankara, Turkey. Mikrobiyol Bul. 2013;47:98-108. [Crossref]

15. Ferreira MSR, da Xavier M PTP, Tinga ACDC, et al. Assessment of Gastroenteric Viruses Frequency in a Children's Day Care Center in Rio De Janeiro, Brazil: A FifteenYear Study (1994-2008). PLoS One. 2012;7:e33754. [Crossref]

16. Timurkan MÖ, Aydın H, Aktaş O. Frequency and molecular characterization of human Norovirus in Erzurum, Turkey. Turk J Med Sci. 2017;47:960-966. [Crossref]

17. Liu L, Moore MD. A survey of analytical techniques for noroviruses. Foods. 2020;9:318. [Crossref]

18. Dimitriadis A, Marshall JA. Evaluation of a commercial enzyme immunoassay for detection of Norovirus in outbreak specimens. Eur J Clin Microbiol Infect Dis. 2005;24:615-618. [Crossref]

19. Zhang Q, Jin M, Cui SX, Liu N, Li L, Duan ZJ. Study on effect of enzyme linked immunosorbent assay kits of Norovirus. Zhonghua Shi Yan He Lin Chuang Bing Du Xue Za Zhi. 2009;23:227-228. [Crossref]

20. Rovida F, Campanini G, Sarasini A, Adzasehoun KMG, Piralla A, Baldanti F. Comparison of immunologic and molecular assays for the diagnosis of gastrointestinal viral infections. Diagn Microbiol Infect Dis. 2013;75:110-111. [Crossref]

21. Utsumi T, Lusida MI, Dinana Z, et al. Molecular epidemiology and genetic diversity of Norovirus infection in children hospitalized with acute gastroenteritis in east Java, Indonesia in 2015-2019. Infect Genet Evol. 2021;88:104703. [Crossref]

22. Andersson M, Kabayiza JC, Elfving K, et al. Coinfection with enteric pathogens in East African children with acute gastroenteritis associations and interpretations. Am J Trop Med Hyg. 2018;98:1566-1570. [Crossref] 